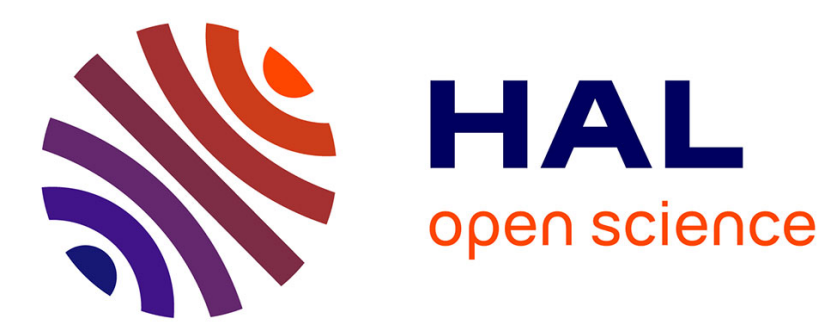

\title{
Anisotropic modeling of the Mullins effect and the residual strain of filled silicone rubber
}

\author{
Marie Rebouah, Grégory Chagnon, Denis Favier
}

\section{To cite this version:}

Marie Rebouah, Grégory Chagnon, Denis Favier. Anisotropic modeling of the Mullins effect and the residual strain of filled silicone rubber. 8th European Conference on Constitutive Models for Rubbers, Jun 2013, San Sebastian, Spain. pp.431-435. hal-00936540

\section{HAL Id: hal-00936540 \\ https://hal.science/hal-00936540}

Submitted on 26 Jan 2014

HAL is a multi-disciplinary open access archive for the deposit and dissemination of scientific research documents, whether they are published or not. The documents may come from teaching and research institutions in France or abroad, or from public or private research centers.
L'archive ouverte pluridisciplinaire HAL, est destinée au dépôt et à la diffusion de documents scientifiques de niveau recherche, publiés ou non, émanant des établissements d'enseignement et de recherche français ou étrangers, des laboratoires publics ou privés. 


\title{
Anisotropic modeling of the Mullins effect and the residual strain of filled silicone rubber
}

\author{
M. Rebouah \& G. Chagnon \& D. Favier \\ Université de Grenoble/CNRS,Lab 3SR, Grenoble, France
}

\begin{abstract}
Many rubber like materials present a stress-softening phenomenon known as Mullins effect. It is characterized by a difference of behavior between the first and second loading and by a residual strain after a first loading. Moreover according to the literature this stress softening is anisotropic. A new constitutive equation is proposed. It relies on the decomposition of the macromolecular network into two parts: chains related together and chains related to fillers. The first part is modeled by a simple hyperelastic constitutive equation whereas the second one is described by a constitutive equation describing both the anisotropic stress softening and the residual strain. A 42 directions discretization is chosen to describe the anisotropic part of the model. An evolution function is introduced in the constitutive equation in each direction to record the history of the material. The equations are written by means of strain invariants in order to build a model easy to implement in a finite element code.

The constitutive equation is finally validated on experimental data.
\end{abstract}

\section{INTRODUCTION}

Despite many different studies the accurate prediction of rubber like materials behavior is still an open issue. These materials are often submitted to cyclic conditions at large strain state and present highly nonlinear phenomena. Three main phenomena can be distinguished.

First the Mullins effect can be idealized as an instantaneous and irreversible stress softening, due to rearrangements in the microstructure of the material that occur when the actual loading exceeds the maximum strain state reached during the last loading. When the previous maximum stretch is exceeded the loading curve turns up and follows the primary curve again up to a new maximum (Mullins, 1969; Gurtin and Francis, 1981; Simo, 1987; Miehe, 1995; Ogden and Roxburgh, 1999).

The second phenomenon is the permanent set, which is characterized by a residual strain, and observed for many rubber like materials (Ogden, 2004; Diani et al., 2006; Merckel et al., 2011). It depends both of the amount of filler and of the maximal strain state reached.

Finally, the third non linear phenomenon is the anisotropy induced by the Mullins effect. It has been observed that the stress softening of a material is maximal for a second loading along the direction of tensile. At the opposite the material present a primary strain stress curve for an orthogonal tensile test after a first loading (Laraba-Abbes et al., 2003; Diani et al., 2006; Itskov et al., 2006; Machado et al., 2012a; Merckel et al., 2013).

Most of the existent model do not treat simultaneously this non linear effects. The constitutive equation developed here, proposes a simple model to take into account Mullins effect, permanent set and induced anisotropy for rubber like materials. Few models proposed in literature to take into account the Mullins effect, the permanent set and the induced anisotropy of a material is the model of Diani et al. (2006); Merckel et al. $(2012,2013)$.

The aim of this paper is to present a stress softening constitutive equation with residual elongation that can be applied on rubber like material. In this way, in Section 2 an experimental study lead on a filled silicone is presented highlighting the induced anisotropy, the stress softening and the residual strain in the material, in Section 3 constitutive equations are developed to take into account the phenomena and comparisons with experimental data and theorical results of the constitutive equations are presented. Finally Section 4 presents some conclusions. 


\subsection{The material}

For this study a Heat Cured Silicone (HCS) also called Hot Temperature Vulcanization (HTV) is used. It contains $30 \%$ of fillers (silica). This filled silicone rubber is vulcanized with a peroxyde starter. A plate of $185 \mathrm{~mm}$ length, $170 \mathrm{~mm}$ width and $2.5 \mathrm{~mm}$ thick is molded and vulacnized under pressure and temperature. Tensile tests were realized on sample of $15 \mathrm{~mm}$ length, $2.5 \mathrm{~mm}$ width and $2.5 \mathrm{~mm}$ thick cut from the rectangular plate.

\subsection{Tensile test}

It is important to carried out tests at a small strain rate to limit the possible effect of the viscoelasticity of the material on the measures of the permanent set. Nevertheless, for this material, cyclic tensile test up to $\lambda=2.5$ (where the stretch represents the actual length of a sample over its initial length) were performed at different strain rates of $0.025 \mathrm{~s}^{-1}, 0.167 \mathrm{~s}^{-1}, 0.833$ $\mathrm{s}^{-1}, 1.667 \mathrm{~s}^{-1}$. It is observed in Fig. 1 that the strain rate does not have any influence on the mechanical behavior of the material since the stress strain curve is identical for the different strain rate. Thus it is assumed that the permanent set measures on this material is only due to an irreversible deformation and not to viscoelasticity.

Then, silicone samples were subjected to periodic loading up to a fixed stretch. These tests were all carried out at the same strain rate of $1 \mathrm{~s}^{-1}$. Each of the specimens was subjected to five loading unloading cycles up to $\lambda=2$. After completion of the fifth unloading cycle, each specimen was then loaded up to a stretch of $\lambda=2.5$. No recovery time was allowed during the 5 loading unloading cycles. This test was performed three times to highlight the repetitiveness of the results at the same constant room temperature of $25{ }^{\circ} \mathrm{C}$. The results can be observed in Fig.2. According to these results, it is known that this silicone presents both non linear effect as Mullins effect and permanent set.

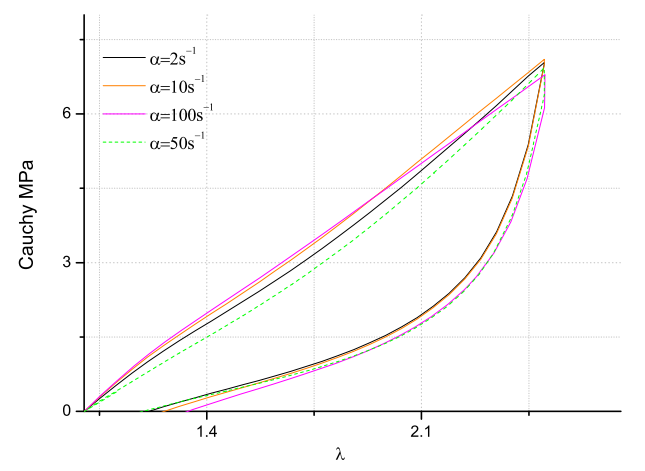

Figure 1: Influence of the strain rate on HTV silicone

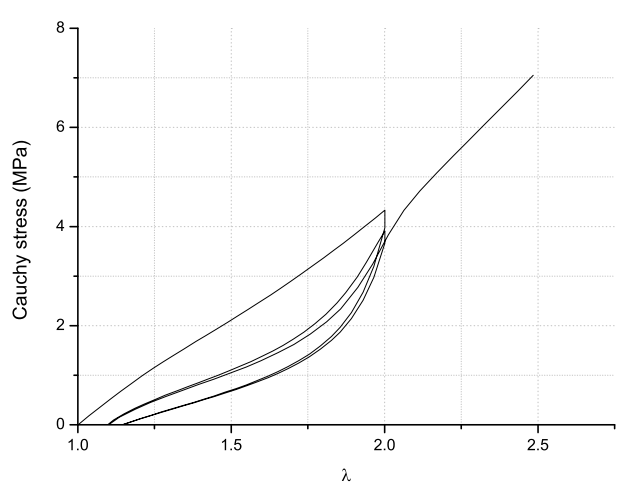

Figure 2: Cyclic tensile on HTV silicone at a strain rate of $1 . \mathrm{s}^{-1}$

\subsection{Tensile tests highlighting induced anisotropy}

In this section, it is proposed to highlight the induced anisotropy of the silicone. First a large sample of silicone is submitted to a pure shear test (Fig3(a)). This large sample of $40 \mathrm{~mm}$ length and $15 \mathrm{~mm}$ width is submitted to a cyclic tensile test up to $\lambda=2$. This test is performed at a strain state of $1 \mathrm{~s}^{-1}$ and a temperature of $25^{\circ} \mathrm{C}$. Then several samples are cut from this large sample, along different orientations compared to the first tensile direction Fig.3(b). Four new samples are obtained, and each one is subjected to a loading unloading cycle up to $\lambda=2.5$ at a strain state of 1 $\mathrm{s}^{-1}$, tests were all performed at a constant room temperature of $25^{\circ} \mathrm{C}$.

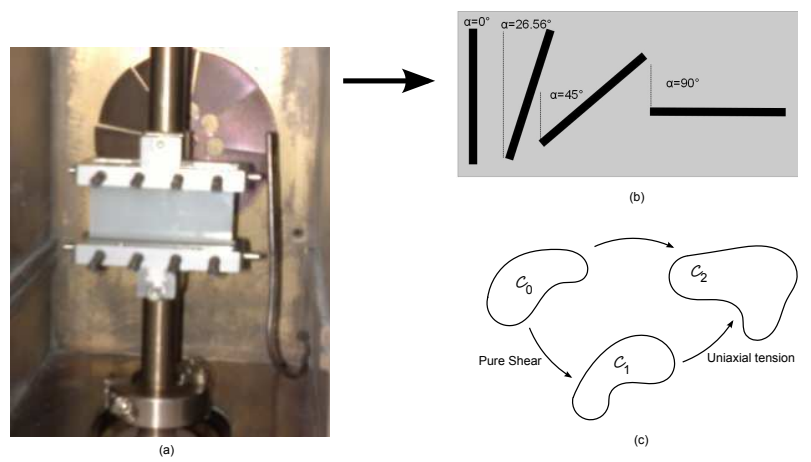

Figure 3: (a) Pure shear test, (b) geometry of the cut specimens inside the pure shear specimen, (c) definition of the configurations, $(\mathrm{C} 0)$ initial configuration, $(\mathrm{C} 1)$ configuration after the pure shear test, (C2) configuration after the pure shear and tensile tests.

By means of this tests, several remarks can be done. First, the influence of the orientation of the samples is highlighted in Fig.4. For this representation it is considered that the initial configuration is $C_{1}$ and not $C_{0}$ (Fig.3(c)), thus the stress softening can be analyzed despite the permanent set induced by the pure shear test and the influence of the orientation is more obvious (It consists in considering that the samples cut in the pure shear specimens are the initial configuration, i.e. suppressing the residual elongation). The orientation of the samples has an important influence 
on the mechanical behavior of the silicone. It is observed that for an orientation of $\alpha=90^{\circ}$ the material has the same behavior as a first loading. That means that no stress softening is observed in the orthogonal direction to the first loading. The stress softening is more important for the orientation of $\alpha=25^{\circ}$ than for the orientation of $\alpha=45^{\circ}$. These tests prove that the Mullins effect induces anisotropy. This results are similar to those obtained by Machado et al. (2012b)

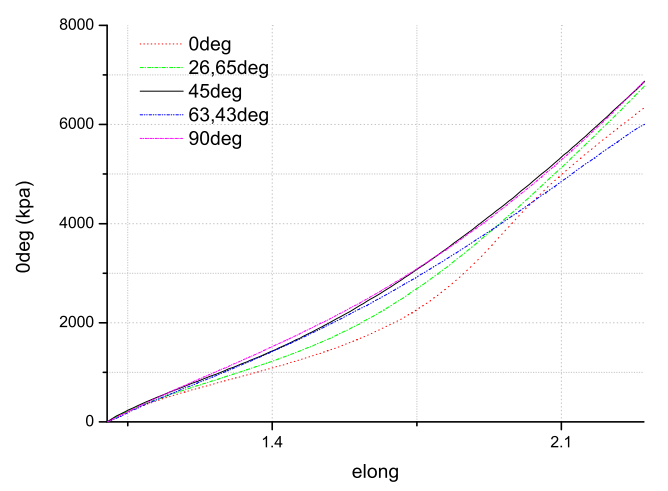

Figure 4: Influence of the sample cut from the large along different orientation

It is also proposed to represent four tensile tests with different orientation by taking into account the all history of the materials since the initial configuration $C_{0}$ (Fig.3(c)). The Fig.5 highlights the same stress softening as the Fig. 4 and also the amount of permanent set endured lasting the pure shear test by the different samples. Thus, it is observed that the residual elongation is more important when the angle between the first and second loadings is weak. Indeed, for an orientation of $\alpha=0^{\circ}$ it can be observed an initial permanent set (due to the pure shear test) of $\lambda_{\text {resid }}=1.136$ and at the opposite for the sample cut at $\alpha=90^{\circ}$ the initial permanent set is equal to zero. This representation proved also that the Mullins effect induced anisotropy. These results are similar to those obtained by Merckel et al. (2013)

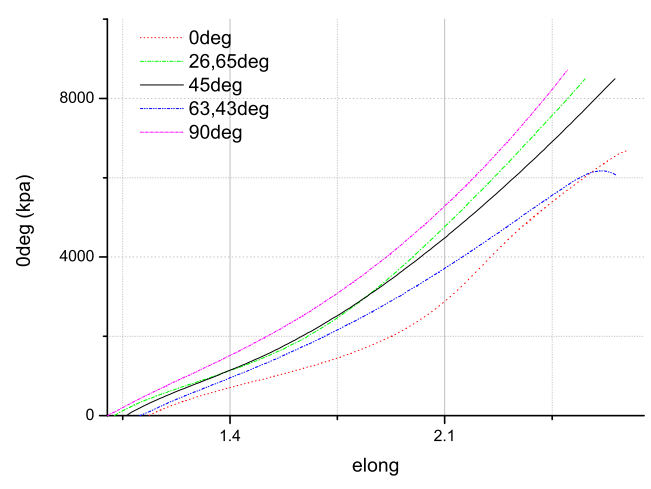

Figure 5: Mechanical behavior of the different samples by taking into account the residual strain endured lasting the pure shear test

\section{EQUIVALENT MODEL CONSTITUTIVE EQUATIONS}

\subsection{General form}

Rebouah et al. (2013) developed a constitutive equation written with strain invariants to predict the behavior of a filled RTV silicone rubber. The strain energy density $\mathcal{W}$ (silicone) is additively decomposed into two parts: one that represents the strain energy of the chains linked to filler $\mathcal{W}_{c f}$ and an other part that represents the strain energy of the chains linked to other chains $\mathcal{W}_{c c}$, the total strain energy density is $\mathcal{W}$ (silicone $)=\mathcal{W}_{c c}+\mathcal{W}_{c f}$. It is considered that only $\left(\mathcal{W}_{c f}\right)$ can evolve with the Mullins effect and take into account the permanent set of the material. As a consequence $\mathcal{W}_{c f}$ must be represented by an anisotropic strain energy function that can record the deformation history of the material. The 42 spatial directions $\mathbf{A}^{(i)}$ repartition proposed by Bazant and $\mathrm{Oh}$ (1986) are used. The dilatation in each direction is defined by means of $\mathbf{I}_{\mathbf{4}}{ }^{(i)}=\mathbf{A}^{(i)} \cdot \mathbf{C A}{ }^{(i)}$. The $\mathbf{A}^{(i)}$ direction is transformed in $\mathbf{a}^{(i)}$ after a transformation by $\mathbf{a}^{(i)}=\mathbf{F A}{ }^{(i)}$ where $\mathbf{F}$ is the deformation gradient. The general form of the strain energy is:

$\mathcal{W}($ silicone $)=\mathcal{W}_{c c}\left(I_{1}, I_{2}\right)+\sum_{i=1}^{42} \omega^{(i)} \mathcal{F}^{(i)} \mathcal{W}_{c f}^{(i)}\left(I_{4}^{(i)}\right)$

The model can be used with any strain energy function. The Mooney (1940) strain energy function is chosen for $\mathcal{W}_{c c}$ where $I_{1}, I_{2}$ are the first and second strain invariants of the right Cauchy-Green deformation tensor $\mathbf{C}$ and $\omega^{(i)}$ represents the weight of each direction, $\mathcal{F}^{(i)}$ is the Mullins effect evolution function and $W_{c f}^{(i)}$ is the strain energy of each chains adapted for the HTV silicone used

$\mathcal{W}_{c f}^{(i)}=\frac{K}{2} \int \sqrt{\frac{I_{4}^{(i)}-1}{I_{4}^{(i)}}} d I_{4}^{(i)}$

Rebouah et al. (2013) proposed an evolution function which depends on the first and fourth invariants with only one material parameter $\eta$. Since the Mullins effect and the permanent set depends both on the maximal deformation record by means of the evolution function, the parameter $\eta$ allowed to represent simultaneously the stress softening and the permanent set of the material. Compared to the model developed by Rebouah et al. (2013) the evolution function can become negative and no restriction is applied to $\mathcal{F}^{(i)}$, thus the permanent set is taking into account. The form of the evolution function is the product of two terms here. The first represents the maximal deformation of each direction of the material and the second 
the triaxiality of the loading. Each term is regulated by a constant power to represent at the best the material. The new form of the evolution function adapted to HTV proposed here:

$\mathcal{F}^{(i)}=1-\eta\left(\frac{I_{4 \max }^{(i)}-I_{4}^{(i)}}{I_{4 \max }^{(i)}-1}\right)^{0.5}\left(\frac{I_{4 \max }^{(i)}}{I_{4 \max }}\right)^{2.5}$

the Cauchy stress tensor is described as

$\boldsymbol{\sigma}_{\text {silicone }}=\boldsymbol{\sigma}_{c c}+\boldsymbol{\sigma}_{c f}-p \mathbf{I}$

where $\boldsymbol{\sigma}_{c c}$ is the part of the Cauchy stress that represents the chains linked to other chains and $\boldsymbol{\sigma}_{c f}$ the part of the Cauchy stress that represent the chains linked to fillers.

$\boldsymbol{\sigma}_{c c}=2 \mathbf{B} \frac{\partial W_{c c}}{\partial I_{1}}+2\left(I_{1} \mathbf{B}-\mathbf{B}^{2}\right) \frac{\partial W_{c c}}{\partial I_{2}}$

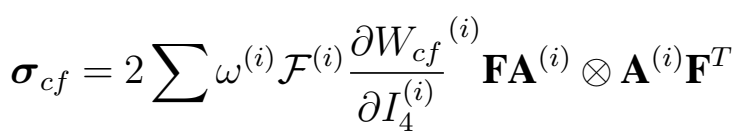

\subsection{HTV on a tensile test}

To validate the model, it is proposed to compare the experimental data obtained during the cyclic tensile test of the HTV silicone and the model. Material parameters were fitted on the experimental data. The values of the mechanical parameter obtained are: $C_{1}=0.35, C_{2}=0.19, \eta=6 ., K=1.6$. According to Fig.6 the results obtained are satisfactory since it can be observed that the Mullins effect and the permanent set are well described by the model.

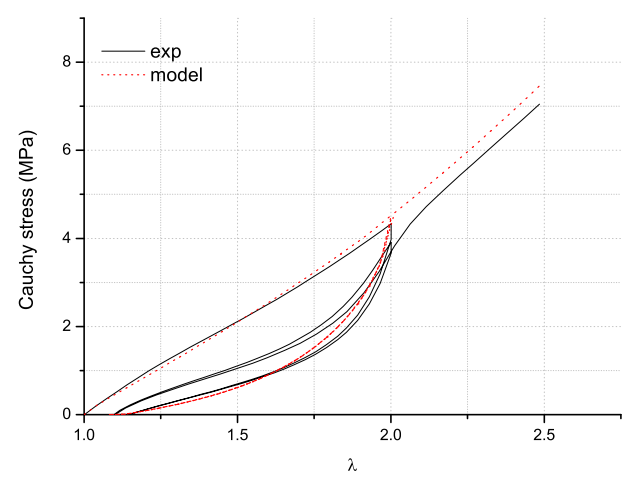

Figure 6: Comparison with experimental data and model

\subsection{HTV on a tensile test after a pure shear test}

In this section, it is proposed to compare the experimental results of the pure shear test followed of tensile test according different orientations with the experimental data. According to the Fig.7 it is observed that the experimental tensile test at $0^{\circ}$ matches to a second loading for the model. In the same way, it is observed that the experimental tensile test at $90^{\circ}$ matches to a virgin curve. For orientations of $25^{\circ}$ and $45^{\circ}$ the curves are between a first or a second loading. It is observed that the model take well into account the induced anisotropy, the Mullins effect and the permanent set since the theorical results and the experimental data are well superimposed.

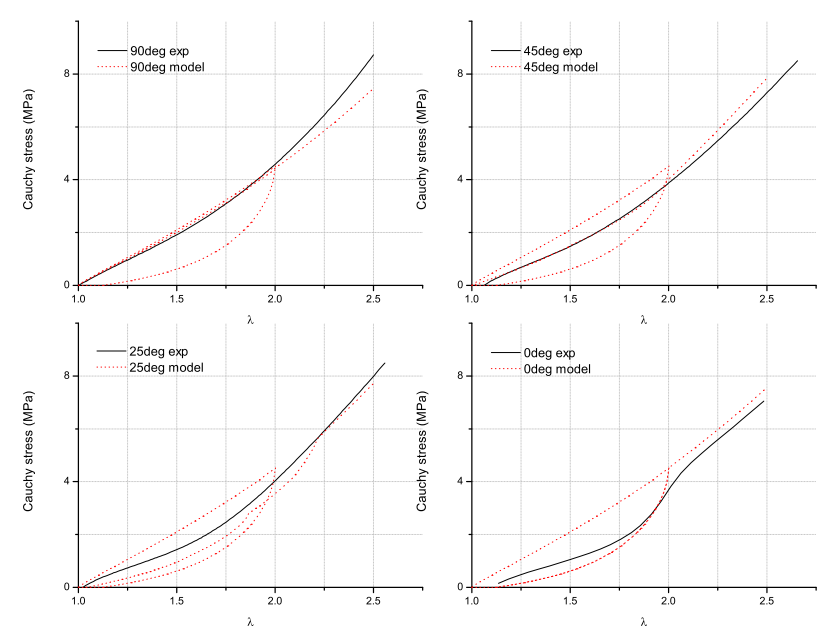

Figure 7: Comparison with experimental oriented data and the model

\section{CONCLUSIONS}

As explained and shown in the present paper a simple model is proposed here to take into account several non linear effects. This model is able to take into account simultaneously the stress softening, the permanent set and the induced anisotropy of a material. Furthermore, due to the expressions of the model, it is easily implemented into a Finite Element code.

\section{REFERENCES}

Bazant, Z. P. and Oh, B. H. (1986). Efficient numerical integration on the surface of a sphere. Z. Angew. Math. Mech., 66, 37-49.

Diani, J., Brieu, M., and Vacherand, J. M. (2006). A damage directional constitutive model for the Mullins effect with permanentset and induced anisotropy. Eur. J. Mech. A/Solids, 25, 483-496.

Gurtin, M. E. and Francis, E. C. (1981). Simple rate-independent model for damage. J. Spacecraft, 18(3), 285-286.

Itskov, M., Haberstroh, E., Ehret, A. E., and Vohringer, M. C. (2006). Experimental observation of the deformation induced anisotropy of the 
Mullins effect in rubber. Kaut Gummi Kunstst , 59(3), 93-96.

Laraba-Abbes, F., Ienny, P., and Piques, R. (2003). A new taylor-made methodology for the mechanical behaviour analysisof rubber like materials: II. application of the hyperelastic behaviour characterization of a carbon-black filled natural rubber vulcanizate. Polymer, 44, 821-840.

Machado, G., Favier, D., and Chagnon, G. (2012a). Determination of membrane stress-strain full fields of bulge tests from SDIC measurements. Theory, validation and experimental results on a silicone elastomer. Exp. Mech., 52, 865-880.

Machado, G., Chagnon, G., and Favier, D. (2012b). Induced anisotropy by the Mullins effect in filled silicone rubber. Mech. Mater., 50, $70-80$.

Merckel, Y., Diani, J., Roux, S., and Brieu, M. (2011). A simple framework for full-network hyperelasticity and anisotropic damage. J. Mech. Phys. Solids, 59, $75-88$.

Merckel, Y., Brieu, M., Diani, J., and Caillard, J. (2012). A Mullins softening criterion for general loading conditions. J. Mech. Phys. Solids, 60, 1257 -1264 .

Merckel, Y., Diani, J., Brieu, M., and Caillard, J. (2013). Constitutive modeling of the anisotropic behavior of mullins softened filled rubbers. Mech. Mater, 57, 30 - 41.

Miehe, C. (1995). Discontinuous and continuous damage evolution in Ogden type large strainelastic materials. Eur. J. Mech., A/Solids, 14, 697-720.

Mooney, M. (1940). A theory of large elastic deformation. J. Appl. Phys., 11, 582-592.

Mullins, L. (1969). Softening of rubber by deformation. Rubber Chem. Technol., 42, 339-362.

Ogden, R. W. (2004). Mechanics of rubberlike solids. In XXI ICTAM, Warsaw, Poland.

Ogden, R. W. and Roxburgh, D. G. (1999). An energy based model of the Mullins effect. In Dorfmann \& Muhr, editor, Constitutive Models for Rubber I. A. A. Balkema., $23-28$.

Rebouah, M., Machado, G., Chagnon, G., and Favier, D. (2013). Anisotropic Mullins stress softening of a deformed silicone holey plate. Mech. Res. Comm., 49, $36-43$.

Simo, J. C. (1987). On a fully three-dimensional finite-strain viscoelastic damage model :formulation and computational aspects. Comp. Meth. Appl. Mech. Engng, 60, 153-173. 